\title{
Pengaruh Jenis Pelarut Terhadap Aktivitas Antioksidan Ekstrak Cair Daun Turi (Sesbania grandiflora)
}

\author{
The Effect of Solvent Types on Antioxidant Activity of Turi (Sesbania grandiflora) \\ Leaves Liquid Extract
}

\author{
Jevon Misael Gerald Masengi*, Gusti Ayu Kadek Diah Puspawati, A.A. Istri Sri Wiadnyani \\ Program Studi Ilmu dan Teknologi Pangan, Fakultas Teknologi Pertanian, \\ Universitas Udayana, Jl. Raya Kampus Unud, Jimbaran, Kuta Selatan, Badung-Bali \\ *Email: jevonmisael159@gmail.com
}

\begin{abstract}
The purpose of this study was to determine the effect of solvent types on antioxidant activity of turi (Sesbania grandiflora) leaves liquid extract and to determine the compatible solvent types which have the highest antioxidant activity of turi leaves liquid extract. The research used a completely randomized design with the treatment of solvent types consisting of 4 level which is: aquadest; acetone 70\%; methanol 70\%; and ethanol $70 \%$. The treatment was repeated four times so that they were obtained 16 experiment units. The data was analyzed with analysis of variance and if the treatment had a significant effect followed by a Duncan's Multiple Range Test. The results showed the type of solvent treatment had a significant effect on antioxidant activity, total flavonoid, total tannin, and vitamin $\mathrm{C}$ content. The best treatment was obtained from turi leaves liquid extract using acetone $70 \%$ solvent which had the highest antioxidant activity of $75.71 \%$ with the value of $\mathrm{IC}_{50} 269.67$, total flavonoid $0.185 \mathrm{mg} \mathrm{QE} / \mathrm{g}$ material, total tannin $0.013 \mathrm{mg}$ TAE/g material and vitamin $\mathrm{C}$ content $0.45 \mathrm{mg} \mathrm{AAE} / \mathrm{g}$ material.
\end{abstract}

Keywords : Antioxidant activity, solvent types, turi leaves.

\section{PENDAHULUAN}

Tanaman turi (Sesbania grandiflora) merupakan tumbuhan yang dikenal masyarakat sebagai tumbuhan sayur dan lalapan. Bagian tanaman turi yang dikonsumsi adalah daun muda, kulit lunak, dan bunga dengan cara ditumis, dikukus atau direbus (Anon., 1979). Sangeetha et al. (2014) melaporkan bahwa ekstrak daun turi memiliki sifat sebagai antioksidan. Antioksidan adalah senyawa pemberi elektron (electron donor) atau reduktan. Beberapa manfaat dari antioksidan terhadap kesehatan adalah menghambat penggumpalan sel darah, merangsang pembentukan produksi nitrit oksida (NO) yang berperan melebarkan pembuluh darah (vasorelaxation) dan juga menghambat pertumbuhan sel kanker (Winarsi, 2007). Manfaat daun turi sebagai antioksidan didapatkan dari komponen bioaktif dan vitamin $\mathrm{C}$ yang terkandung di dalamnya. Komponen bioaktif yang ditemukan pada daun turi meliputi: fenolik, flavonoid dan tanin (Padmalochana dan Rajan, 2014; Sangeetha et al., 2014). Untuk mendapatkan senyawa antioksidan dapat dilakukan dengan ekstraksi.

Faktor-faktor yang berpengaruh terhadap ekstraksi adalah metode ekstraksi (Dutra et al., 2008), lama ekstraksi (Kemit et al., 2016), konsentrasi pelarut (Suhendra et al., 2019), dan 
jenis pelarut (Suryani et al., 2016). Salah satu metode ekstraksi yang sering digunakan adalah maserasi. Kemit et al. (2016) melaporkan bahwa waktu maserasi mempengaruhi total flavonoid serta aktivitas antioksidan pada ekstrak daun alpukat. Waktu maserasi 30 jam menghasilkan total flavonoid serta aktivitas antioksidan yang lebih tinggi dibandingkan 18, 24, dan 36 jam pada pelarut aseton, metanol, dan etanol. Berdasarkan penelitian yang dilakukan oleh Suryani et al. (2016), jenis pelarut yang digunakan mempengaruhi aktivitas antioksidan yang dihasilkan. Aktivitas antioksidan tertinggi pada ekstrak daun matoa (Pometia pinnata) didapakan menggunakan pelarut aseton. Senyawa yang bersifat polar akan larut dalam pelarut polar, sedangkan senyawa yang bersifat semi polar akan larut ke dalam pelarut semi polar, serta senyawa yang bersifat non polar akan larut ke dalam pelarut non polar (Harborne, 1987). Komponen bioaktif yang diekstrak dari bahan selain bersifat polar dan non polar ada juga yang bersifat semi polar (Handojo, 1995). Pelarut polar yang biasa digunakan untuk ekstraksi senyawa polar antara lain air, metanol, dan etanol (Sudarmadji et al., 1997). Pelarut aseton merupakan pelarut semi polar yang dapat digunakan untuk mengekstraksi senyawa semi polar (Handojo, 1995).

Menurut Seo et al. (2014) air merupakan jenis pelarut yang tepat digunakan untuk mengekstrak flavonoid secara maserasi pada ekstrak daun jambu biji, selain itu air juga murah dan mudah didapatkan. Fatiha et al. (2012) melaporkan bahwa aseton $75 \%$ merupakan pelarut yang paling sesuai digunakan untuk mengesktrak senyawa flavonoid secara maserasi pada ekstrak Algerian mint, sedangkan Syukriah et al. (2014) melaporkan bahwa aktivitas antioksidan tertinggi didapatkan menggunakan pelarut metanol $70 \%$ pada ekstrak manjakani secara solvent extraction. Anggrainingsih dan Farida (2013) juga melaporkan bahwa etanol $70 \%$ merupakan pelarut yang tepat untuk digunakan dalam mengekstrak senyawa flavonoid dan mendapatkan aktivitas antioksidan tertinggi secara maserasi pada ekstrak daun sirih. Hal ini disebabkan karena senyawa fenol dan flavonoid yang terkandung pada masing-masing bahan berbeda. Sampai saat ini belum dilaporkan jenis pelarut yang tepat untuk mendapatkan aktivitas antioksidan tertinggi yang terdapat pada daun turi. Oleh karena itu perlu dilakukan penelitian dengan tujuan untuk mengetahui apakah jenis pelarut berpengaruh terhadap aktivitas antioksidan ekstrak cair daun turi dan menentukan pelarut yang tepat untuk memperoleh ekstrak cair daun turi dengan aktivitas antioksidan tertinggi.

\section{METODE PENELITIAN}

\section{Tempat dan Waktu}

Penelitian dilaksanakan di Laboratorium Analisis Pangan, Laboratorium Pengolahan Pangan dan Laboratorium Rekayasa Proses dan Pengendalian Mutu, Fakultas Teknologi Pertanian, Universitas Udayana, Kampus Jalan P. B. Sudirman, Denpasar. Penelitian dilaksanakan pada bulan Juni - Agustus 2019.

\section{Bahan dan Alat}

Bahan yang digunakan dalam penelitian ini adalah daun turi muda (5-8 tangkai dari pucuk yang warnanya hijau muda) yang diperoleh dari 
Renon, Denpasar. Bahan kimia yang digunakan adalah akuades, aseton 70\% (Merck), metanol 70\% (Merck), etanol 70\% (Merck), 1-picrylhydrazyl-2diphenyl (DPPH) (Himedia), $\mathrm{NaNO}_{2}$ (Merck), $\mathrm{AlCl}_{3}$ (Merck), $\mathrm{NaOH}$ (Merck), $\mathrm{Na}_{2} \mathrm{CO}_{3}$ (Merck), asam asetat (Merck), ammonium hidroksida (Merck), asam sulfat pekat (Merck), natrium fosfat (Merck), amonium molibdat (Merck), dan reagen folin Denis (Merck).

Peralatan yang digunakan dalam penelitian ini adalah oven (Blue M), blender (Miyako), timbangan analitik (Shimadzu ATY224), ayakan 60 mesh, spektrofotometer (Genesys 10S UV-Vis), kertas saring Whatman No.1, vortex, water bath (Memmert), desikator, dan alat-alat gelas.

\section{Rancangan Percobaan}

Percobaan ini menggunakan rancangan acak lengkap (RAL) dengan perlakuan jenis pelarut, yaitu: P1 (Akuades), P2 (Aseton 70\%), P3 (Metanol 70\%), dan P4 (Etanol 70\%). Perlakuan diulang sebanyak empat kali sehingga didapatkan 16 unit percobaan. Data yang diperoleh kemudian dianalisis menggunakan sidik ragam dan bila perlakuan berpengaruh nyata, maka dilanjutkan dengan Duncan's Multiple Range Test (DMRT) (Steel dan Torrie, 1993).

\section{Pelaksanaan Penelitian}

\section{Persiapan Bahan Baku}

Daun turi yang sudah disortasi dicuci bersih dan ditiriskan, kemudian dikeringkan dengan menggunakan oven pada suhu $50^{\circ} \mathrm{C}$ selama 3 jam hingga kering. Selanjutnya dihaluskan dengan menggunakan blender dan kemudian diayak dengan ayakan 60 mesh untuk menghasilkan bubuk daun turi. (Lestari et al., 2018 yang dimodifikasi).

\section{Ekstraksi Bubuk Daun Turi}

Bubuk daun turi diekstrak menggunakan metode maserasi. Sejumlah bahan ditambahkan pelarut sesuai perlakuan (akuades, aseton 70\%, metanol 70\%, dan etanol 70\%) dengan perbandingan bahan dengan pelarut adalah 1:10 (b/v), kemudian dimaserasi selama 30 jam pada suhu kamar. Setelah itu, larutan disaring dengan kertas saring whatman no 1 untuk mendapatkan ekstrak cair (Widarta dan Arnata, 2017 yang dimodifikasi).

\section{HASIL DAN PEMBAHASAN}

\section{Kadar Total Flavonoid Ekstrak Cair Daun Turi}

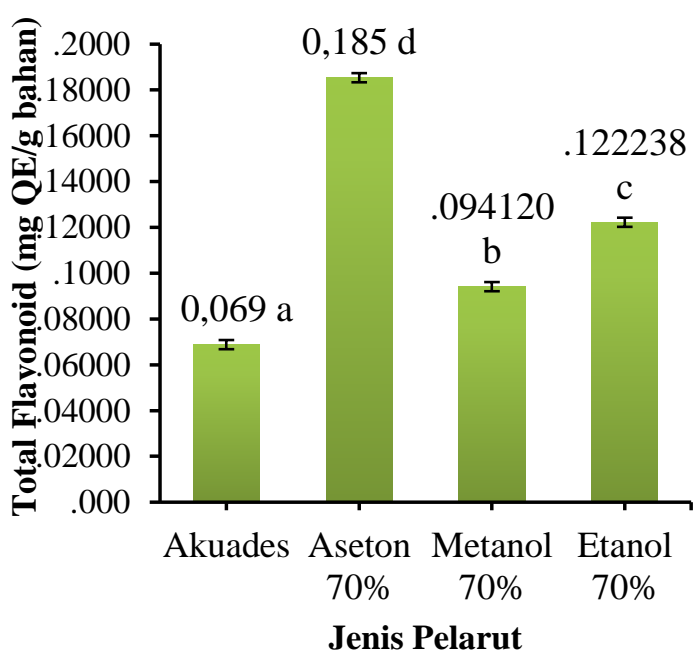

Keterangan: Notasi yang sama pada diagram batang yang berbeda menunjukkan pengaruh perlakuan yang tidak berbeda nyata $(\mathrm{p}>0,05)$.

Gambar 1. Nilai rata-rata total flavonoid ekstrak cair daun turi pada beberapa jenis pelarut.

Hasil sidik ragam menunjukkan bahwa perlakuan jenis pelarut berpengaruh nyata $(p<0,05)$ 
terhadap total flavonoid ekstrak cair daun turi. Gambar 1 menunjukkan bahwa total flavonoid tertinggi diperoleh pada pelarut aseton $70 \%$ yaitu sebesar $0,185 \mathrm{mg} \mathrm{QE} / \mathrm{g}$ bahan, sedangkan total flavonoid terendah diperoleh pada pelarut akuades yaitu sebesar 0,069 mg QE/g bahan. Hal ini dapat disebabkan karena pelarut aseton $70 \%$ yang memiliki kepolaran lebih rendah dibandingakan jenis pelarut lainnya lebih cocok mengekstrak senyawa flavonoid pada daun turi. Harborne (1987) menyatakan bahwa senyawa flavonoid terbagi menjadi beberapa jenis yang memiliki tingkat kepolaran yang berbeda-beda, tingkat kepolaran dipengaruhi oleh posisi dan jumlah gugus hidroksil flavonoid. Tingkat kepolaran mempengaruhi kelarutan flavonoid pada pelarut yang digunakan. Dengan demikian dapat dilaporkan senyawa flavonoid yang ada pada daun turi memiliki tingkat kepolaran yang lebih mendekati pelarut aseton $70 \%$.

Hasil ini didukung dengan penelitian Dirar et al. (2018), bahwa aseton mengekstrak senyawa flavonoid lebih baik dibandingkan air dan metanol pada Begheil (Blepharis linariifolia Pers.). Aseton juga menghasilkan total flavonoid yang lebih tinggi dari metanol, etanol, dan akuades pada Limnophila aromatica (Do et al., 2013). Hasil penelitian Makhlouf et al. (2013) juga menunjukkan total flavonoid tertinggi didapatkan menggunakan pelarut aseton pada ekstrak terung (Solanum melongena). Dengan demikian dapat dikatakan senyawa flavonoid pada daun turi memiliki kemiripan dengan senyawa flavonoid pada Begheil, Limnophila aromatica, dan ekstrak terung.

\section{Kadar Total Tanin Esktrak Cair Daun Turi}

Hasil sidik ragam menunjukkan bahwa perlakuan jenis pelarut berpengaruh nyata $(p<0,05)$ terhadap total tanin ekstrak cair daun turi. Gambar 2 menunjukkan bahwa total tanin tertinggi diperoleh pada pelarut aseton $70 \%$ yaitu sebesar 0,013 mg TAE/g bahan, sedangkan total tanin terendah diperoleh pada pelarut akuades yaitu sebesar 0,002 mg TAE/g bahan.



Keterangan: Notasi yang sama pada diagram batang yang berbeda menunjukkan pengaruh perlakuan yang tidak berbeda nyata $(\mathrm{p}>0,05)$.

Gambar 2. Nilai rata-rata total tanin ekstrak cair daun turi pada beberapa jenis pelarut.

Konstanta dielektrik akuades, aseton, metanol, dan etanol berturut-turut adalah 80,2; 20,7; 32,6; dan 24,3. Konstanta dielektrik menunjukkan kepolaran suatu pelarut, dimana semakin tinggi konstanta dielektrik suatu pelarut maka semakin polar pelarut tersebut. Hal ini bisa diasosiasikan dengan kaidah like dissolved like dimana pelarut aseton yang memiliki kepolaran lebih rendah lebih cocok untuk mengekstrak 
senyawa tanin pada daun turi dibandingkan pelarut yang memiliki kepolaran lebih tinggi. Menurut Mokrani dan Madani (2016), aseton merupakan pelarut yang paling tepat untuk mengekstraksi senyawa fenolik seperti tanin terkondensasi. Dengan demikian dapat dilaporkan senyawa tanin yang ada pada daun turi memiliki tingkat kepolaran yang lebih mendekati pelarut aseton $70 \%$.

Hal ini didukung dengan penelitian Makhlouf et al. (2013), bahwa pelarut aseton menghasilkan total tanin yang lebih tinggi dibandingkan dengan etanol dan metanol pada konsentrasi yang sama pada ekstrak terung (Solanum melongena). Pelarut aseton juga menghasilkan total tanin tertinggi pada beach pea (Lathyrus maritimus L.) (Chavan dan Amarowicz, 2013). Hasil penelitian Mokhtarpour et al. (2014) juga menunjukkan bahwa aseton menghasilkan total tanin yang lebih tinggi dari etanol dan metanol serta akuades menghasilkan total tanin yang paling rendah pada pistachio by-products (Pistacia vera L.).

\section{Kadar Vitamin C Ekstrak Cair Daun Turi}

Hasil sidik ragam menunjukkan bahwa perlakuan jenis pelarut berpengaruh nyata $(p<0,05)$ terhadap kadar vitamin $\mathrm{C}$ ekstrak cair daun turi. Gambar 3 menunjukkan bahwa kadar vitamin C tertinggi diperoleh pada pelarut aseton $70 \%$ yaitu sebesar 0,45 mg AAE/g bahan, sedangkan kadar vitamin $\mathrm{C}$ terendah diperoleh pada pelarut akuades yaitu sebesar $0,15 \mathrm{mg}$ AAE/g bahan. Hasil menunjukkan bahwa pelarut aseton yang memiliki kepolaran lebih rendah dapat mengekstrak vitamin C lebih baik. Hal ini dapat disebabkan karena pelarut aseton $70 \%$ memiliki tingkat kepolaran yang mendekati vitamin $\mathrm{C}$ pada daun turi. Menurut Troy (2005), aseton merupakan pelarut yang bersifat semi-polar yang dapat menarik senyawa polar dan semi-polar.



Keterangan: Notasi yang sama pada diagram batang yang berbeda menunjukkan pengaruh perlakuan yang tidak berbeda nyata $(p>0,05)$.

Gambar 3. Nilai rata-rata kadar vitamin C ekstrak cair daun turi pada beberapa jenis pelarut.

Hal ini didukung oleh penelitian Kathirvel dan Sujatha (2012), bahwa kadar vitamin C didapatkan lebih tinggi dengan menggunakan pelarut aseton dibandingkan metanol dan air pada ekstrak daun Dryopteris cochleata. Kadar vitamin C pada ekstrak aseton tomat juga ditemukan lebih tinggi dari ekstrak etanolnya (Eveline et al., 2014). Hasil penelitian Verdiana et al. (2018) juga menunjukkan bahwa kadar vitamin $\mathrm{C}$ pada ekstrak kulit buah lemon (Citrus limon (Linn.) Burm F.) 
didapatkan lebih tinggi menggunakan pelarut aseton dibandingkan etanol, metanol, dan akuades.

\section{Aktivitas Antioksidan Ekstrak Cair Daun Turi}

Hasil sidik ragam menunjukkan bahwa perlakuan jenis pelarut berpengaruh nyata $(p<0,05)$ terhadap aktivitas antioksidan ekstrak cair daun turi. Gambar 4 menunjukkan bahwa aktivitas antioksidan tertinggi diperoleh pada pelarut aseton $70 \%$ yaitu sebesar $75,71 \%$, sedangkan aktivitas antioksidan terendah diperoleh pada pelarut akuades yaitu sebesar $37,27 \%$.



Keterangan: Notasi yang sama pada diagram batang yang berbeda menunjukkan pengaruh perlakuan yang tidak berbeda nyata $(\mathrm{p}>0,05)$.

Gambar 4. Nilai rata-rata aktivitas antioksidan ekstrak cair daun turi pada beberapa jenis pelarut.

Hal ini dikarenakan semakin banyak senyawa flavonoid, tanin, dan vitamin $\mathrm{C}$ yang terekstrak maka semakin tinggi aktivitas antioksidan ekstrak cair daun turi. Hasil penelitian menunjukkan bahwa aktivitas antioksidan sejalan dengan data total flavonoid, total tanin dan kadar vitamin $\mathrm{C}$ yang paling tinggi pada pelarut aseton. Senyawa-senyawa tersebut berfungsi sebagai antioksidan.

Hasil ini sesuai dengan penelitian Gowri dan Vasantha (2010), dimana pelarut aseton 70\% menghasilkan total fenolik yang lebih tinggi dibandingkan pelarut etanol $50 \%$ pada ekstrak daun turi, sehingga pelarut aseton $70 \%$ menghasilkan aktivitas antioksidan yang lebih tinggi juga. Hal serupa juga dilaporkan dalam penelitian Yulistian et al. (2015), bahwa pelarut aseton mengekstrak senyawa fenolik paling tinggi sehingga menghasilkan aktivitas antioksidan paling tinggi pada biji kacang tunggak (Vigna unguiculata (L.) Walp).

Berdasarkan hasil aktivitas antioksidan yang didapatkan, pelarut aseton $70 \%$ merupakan pelarut yang memiliki persentase aktivitas antioksidan tertinggi. Aktivitas antioksidan tersebut dapat juga dilihat dari $\mathrm{IC}_{50}$. $\mathrm{IC}_{50}$ menggambarkan besarnya konsentrasi sampel yang mampu menghambat radikal bebas (DPPH) sebanyak 50\%. Semakin kecil nilai $\mathrm{IC}_{50}$ maka kemampuan antioksidan semakin baik (Senevirathne et al., 2006). Hasil $\mathrm{IC}_{50}$ yang didapatkan pada ekstrak cair daun turi menggunakan aseton $70 \%$ adalah 269,67 ppm yang termasuk dalam kategori lemah (Molyneux, 2004 dalam Sami et al., 2019).

\section{KESIMPULAN DAN SARAN}

\section{Kesimpulan}

1. Jenis pelarut berpengaruh nyata terhadap total flavonoid, total tanin, kadar vitamin $\mathrm{C}$ dan aktivitas antioksidan dari ekstrak cair daun turi. 
2. Hasil terbaik didapatkan pada pelarut aseton $70 \%$ yang menghasilkan aktivitas antioksidan sebesar 75,71\% dengan nilai $\mathrm{IC}_{50} 269,67 \mathrm{ppm}$, total flavonoid $0,185 \mathrm{mg} \mathrm{QE} / \mathrm{g}$ bahan, total tanin 0,013 $\mathrm{mg} \mathrm{TAE} / \mathrm{g}$ bahan, dan kadar vitamin C 0,45 mg AAE/ g bahan.

\section{Saran}

Berdasarkan hasil penelitian ini disarankan untuk mengekstrak daun turi menggunakan pelarut aseton $70 \%$ dan perlu dilakukan penguapan pelarut.

\section{DAFTAR PUSTAKA}

Anggrainingsih, T. P. and Y. Farida. 2013. Total phenolic, flavonoids content and antioxidant activity of the ethanolic extract of betel leaf (Piper betle L.). The International Conference in Nanotechnology in Jakarta.

Anonimus. 1979. Tropical Legumes: Recources for the Future. National Academies, Washington D. C.

Chavan, U. D. and R. Amarowicz. 2013. Effect of various solvent systems on extraction of phenolics, tannins and sugars from beach pea (Lathyrus maritimus L.). International Food Research Journal. 20(3):1139-1144.

Dirar, A. I., D. H. M. Alsaadi, M. Wada, M. A. Mohamed, T. Watanabe, and H. P. Devkota. 2018. Effects of extraction solvents on total phenolic and flavonoid contents and biological activities of extracts from Sudanese medicinal plants. South African Journal of Botany.

Do, Q. D., L. H. Huynh, A. E. Angkawijaya, Phuong Lan Tran-Nguyen, Y. H. Ju, F. E. Soetaredjo, and S. Ismadji. 2013. Effect of extraction solvent on total phenol content, total flavonoid content, and antioxidant activity of Limnophila aromatica. Journal of Food and Drug Analysis 22:296-302.

Dutra, R. C., M. N. Leite, and N. R. Barbosa. 2008. Quantification of phenolic constituents and antioxidant activity of Pterodon emarginatus vogel seeds. International Journal of Molecular Sciences 9(4):606-614.

Eveline, T. M. Siregar, dan Sanny. 2014. Studi aktivitas antioksidan pada tomat (Lycopersicon esculentum) konvensional dan organik selama penyimpanan. Prosiding Seminar Nasional Sains dan Teknologi. 5:22-28.

Fatiha, B., M. Khodir, D. Farid, R. Tiziri, B. Karima, O. Sonia, and C. Mohamed. 2012. Optimisation of solvent extraction of antioxidants (phenolic compounds) from Algerian mint (Mentha spicata L.). Pharmacognosy Communications. 2(4):7286.

Gowri, S. S. and K. Vasantha. 2010. Free radical scavenging and antioxidant activity of leaves from agathi (Sesbania grandiflora) (L.) Pers. American-Eurasian Journal of Scientific Research 5(2):114-119.

Handojo, L. 1995. Teknologi Kimia. PT Pradya Paramita, Jakarta.

Harborne, J. B. 1987. Metode Fitokimia. Penuntun Cara Modern Menganalisis Tumbuhan. ITB, Bandung.

Kathirvel, A. and V. Sujatha. 2012. Phytochemical studies, antioxidant activities and identification of active compounds using GC-MS of Dryopteris cochleata leaves. Arabian Journal of Chemistry 9(2):14351442.

Kemit, N., I W. R. Widarta, dan K. A. Nocianitri. 2016. Pengaruh jenis pelarut dan waktu maserasi terhadap kandungan senyawa flavonoid dan aktivitas antioksidan ekstrak daun alpukat (Persea Americana Mill). Jurnal Ilmu dan Teknologi Pangan $5(2): 130-141$

Lestari, D. M., N. Mahmudati, Sukarsono, Nurwidodo, dan Husamah. 2018. Aktivitas antioksidan ekstrak fenol daun gayam (Inocarpus fagiferus Fosb). Biosfera 35(1):37-43.

Makhlouf, L. B., L. Medouni, S. M. Adrar, L. Arkoub, and K. Madani. 2013. Effect of solvents extraction on phenolic activity 
content and antioxidant of the byproduct of eggplant. Industrial Crops and Products. 49:668-674.

Mokhtarpour, A., A. A. Naserian, R. Valizadeh, M. Danesh Mesgaran and F. Pourmollae. 2014. Extraction of phenolic compounds and tannins from pistachio by-products. Annual Research \& Review in Biology. 4(8):1330-1338.

Mokrani, A. and K. Madani. 2016. Effect of solvent, time and temperature on the extraction of phenolic compounds and antioxidant capacity of peach (Prunus persica L.) fruit. Separation and Purification Technology. 162:68-76.

Padmalochana, K. and M. S. D. Rajan. 2014. Antimicrobial activity of aqueous, ethanol and acetone extracts of Sesbania grandiflora leaves and its phytochemical characterization. Int. Journal of Pharma Sciences and Research. 5(12):957-962.

Sami, F. J., N. H. Soekamto, Firdaus, dan J. Latip. 2019. Uji aktivitas antioksidan ekstrak alga coklat Sargassum polycystum dan Turbinaria deccurens asal pulau dutungan Sulawesi Selatan terhadap radikal DPPH. Jurnal Kimia Riset. 4(1):1-6.

Sangeetha, A., G. S. Prasath, and S. Subramanian. 2014. Antihyperglicemic and antioxidant potential of Sesbania grandiflora leaves studied in STZ induced experimental diabetic rats. Int. Journal of Pharmaceutical Sciences and Research. 5(6):2266-2275.

Senevirathne, M., S. Kim, N. Siriwardhana, J. Ha, K. Lee, and Y. Jeon. 2006. Antioxidant potential of Ecklonia cava on reactive oxygen species scavenging, metal chelating, reducing power and lipid peroxidation inhibition. Food Science and Technology International. 12:27-38.

Seo, J., S. Lee, M. L. Elam, S. A. Johnson, J. Kang, and B. H. Arjmandi. 2014. Study to find the best extraction solvent for use with guava leaves (Psidium guajava L.) for high antioxidant efficacy. Food Science \& Nutrition. 2(2): 174-180.

Steel, R. G. D. dan J. H. Torrie. 1993. Prinsip dan Prosedur Statistika Suatu Pendekatan
Biometrik. Penerjemah B. Sumantri. PT. Gramedia Pustaka, Jakarta.

Sudarmadji, S., B. Haryono, dan Suhardi. 1997. Prosedur Analisis untuk Bahan Makanan dan Pertanian. Liberty, Yogyakarta.

Suhendra, C. P., I W. R. Widarta, dan A. A. I. S. Wiadnyani. 2019. Pengaruh konsentrasi etanol terhadap aktivitas antioksidan ekstrak rimpang ilalang (Imperata cylindrica (L) Beauv.) pada ekstraksi menggunakan gelombang ultrasonik. Jurnal Ilmu dan Teknologi Pangan. 8(1):27-35.

Suryani, N. C., D. G. M. Permana, dan A. A. G. N. A. Jambe. 2016. Pengaruh jenis pelarut terhadap kandungan total flavonoid dan aktivitas antioksidan ekstrak daun matoa (Pometia pinnata). Jurnal Ilmu dan Teknologi Pangan. 5(1):1-10.

Syukriah, A. R. N., M. S. Liza, Y. Harisun, and A. A. M. Fadzillah. 2014. Effect of solvent extraction on antioxidant and antibacterial activities from Quercus infectoria (manjakani). International Food Research Journal. 21(3):1067-1073.

Troy, D.B. 2005. The Science and Practice of Pharmacy. Lippincott Williams and Wilikins, Philadelphia.

Verdiana, M., I W. R. Widarta, dan I D. G. M. Permana. 2018. Pengaruh jenis pelarut pada ekstraksi menggunakangelombang ultrasonik terhadap aktivitas antioksidan ekstrak kulit buah lemon (Citrus limon (Linn.) Burm F.). Jurnal Ilmu dan Teknologi Pangan. 7(4):213-222.

Widarta, I W. R. dan I W. Arnata. 2017. Ekstraksi komponen bioaktif daun alpukat dengan bantuan ultrasonik pada berbagai jenis dan konsentrasi pelarut. Agritech. 37(2):149157.

Winarsi, H. 2007. Antioksidan Alami dan Radikal Bebas. Kanisius, Yogyakarta.

Yulistian, D. P., E. P. Utomo, S. M. Ulfa, dan E. Yusnawan. 2015. Studi pengaruh jenis pelarut terhadap hasil isolasi dan kadar senyawa fenolik dalam biji kacang tunggak (Vigna unguiculata (L.) Walp) 
